\title{
Bioaugmentation with Phenol-Degrading Bacteria (PDB) as a Strategy for Improving Start-Up and Stability of Sequencing Biofilm Batch Reactor (SBBR) for Coal Gasification Wastewater (CGW) Treatment
}

\author{
Haifeng Zhuang ${ }^{1}$, Fang Fang ${ }^{2 *}$ \\ ${ }^{1}$ Key Laboratory of Recycling and Eco-Treatment of Waste Biomass of Zhejiang Province, \\ Zhejiang University of Science and Technology, Hangzhou, China \\ ${ }^{2}$ Institute of Advanced Technology of Heilongjiang Academy of Sciences, Haerbin, China
}

Received: 13 October 2019

Accepted: 1 December 2019

\begin{abstract}
Coal gasification wastewater (CGW) is one of the most prevalent industrial effluents in China. It contains hundreds to thousands of milligram phenolic compounds per liter, becoming an important threat to the ecological environment. This study was conducted to evaluate the effectiveness of bioaugmentation with phenol-degrading bacteria (PDB) on improving start-up and stability of sequencing biofilm batch reactor (SBBR) for CGW treatment. The augmented SBBR, with a shortened start-up time of 13 days, showed considerably higher pollutant removal. The superiority of augmented SBBR persisted during the whole operation, with $\mathrm{COD}$, total phenols (TPh) and $\mathrm{NH}_{3}-\mathrm{N}$ efficiencies of $86 \%, 89 \%$ and $35 \%$, respectively, compared to $70 \%, 75 \%$ and $22 \%$ for non-augmented SBBR. Under the inhibition of a high concentration of phenolic compounds, the augmented SBBR presented a stronger resistant capability and less recovery time due to inoculating additional PDB. Microbial community analysis revealed that $13.9 \%$ of PDB in activated sludge and $10.8 \%$ in biofilm as dominant populations, which in turn determined the overall performance of the biosystem, resulting in an efficiently augmented reactor for CGW treatment. The discoveries in this study will facilitate successful development of such bioaugmentation systems and can provide some guidance for practical bioprocesses.
\end{abstract}

Keywords: bioaugmentation, coal gasification wastewater, phenol-degrading bacteria, start-up, sequencing biofilm batch reactor

*e-mail: 286339399@qq.com 


\section{Introduction}

Due to increasing awareness on environmental issues and tight environmental regulations in China $[1,2]$, CGW treatment urgently demands efficient and cost-effective treatment. Various treatment techniques such as physical adsorption, biological degradation and advanced oxidation have been developed and applied to remove toxic and refractory pollutants from CGW. Among these options [3], biological methods were especially preferred on account of much lower costs and dramatic sustainability [4]. However, owing to the presence of massive refractory and toxic compounds (such as phenolic compounds, and nitrogen-, oxygenand sulfur-containing heterocyclic compounds), the conventional activated sludge process was seriously inhibited, leading to insufficient and unstable pollutant removal $[5,6]$. Of these contaminants, phenolic compounds were the most vital toxicants, accounting for $40-60 \%$ of total organic carbon, and high phenols usually caused irreversible oxidative damage to microbes [7]. In the influent to the biological process, the concentration of phenolic compounds fluctuated in the range of $500 \mathrm{mg} / \mathrm{L}-3000 \mathrm{mg} / \mathrm{L}$, which far exceeded the tolerant threshold of the aerobic process [6]. In addition to the biotoxicity, the wastewater was characterized for the obviously insufficient biodegradability $\left(\mathrm{BOD}_{5} / \mathrm{COD}=0.22-0.28\right)$, resulting in great difficulty for biological treatment [8]. Therefore, it revealed great necessity for the augmentation of the biological process for CGW treatment.

Bioaugmentation with specific bacteria was an efficient and effective strategy for improving the removal efficiency of recalcitrant organics [9]. Bacterial strains specifically degrading phenol, pyridine or quinoline have been isolated for enhancing coal chemical industry wastewater treatment [10]. The augmented biosystem always showed improved pollutant removal efficiencies in different degrees [11]. In addition to bacteria, fungal bioaugmentation was also applied for further enhancing biosystems, leading to promoted performance on CGW treatment [12]. In order to enhance the degradation of recalcitrant organics in practical wastewater, bacterial mixture was also employed [13]. It was apparent that previous researchers devoted much investigation to improving the performance of a biosystem with special bacteria and technology convergence. In fact, the initiating and performance stability of the biological process was primarily for practical engineering. However, there is little literature about accelerating start-up and strengthening stability of a biosystem with bioaugmentation technology, especially for enhancing CGW treatment.

As an important communication process among microbes, quorum sensing (QS) participated in controlling bacterial behaviors, i.e., bioluminescence, biofilm development, and public good production [14]. Furthermore, facing the challenge of toxic and refractory contaminates, QS could upregulate the secretion of extracellular substances and aggregation of bacteria to improve biosystem resistance [15]. Simultaneously, it was reported that $\mathrm{N}$-acyl-homoserine lactones (AHLs) were the main autoinducer among gramnegative bacteria, and directly indicated the intensity of QS [16]. Thus bioaugmentation with specialized bacteria could be effectively reflected by AHLs.

In current research, in order to facilitate the QS effect, SBBR with high mixed liquor suspended solid concentration was adopted for CGW treatment. The influence of bioaugmentation with PDB on SBBR start-up and the performance robustness under phenolic shock load were respectively investigated. Correspondingly, the QS intensity was also compared between reactors in different stages in order to further explore biosystem resistance. Finally, the influence of bioaugmentation with PDB on the diversity of the microbial community in SBBR was investigated by the analysis of the dominant microbial community.

\section{Materials and Methods}

\section{Characteristics of CGW and Seed Sludge}

The CGW was collected from the effluent of an upflow anaerobic sludge bed reactor in Longhua Coal Chemical Industry Co., Ltd. (Harbin, China). The concentrations of the main pollutants in raw wastewater were as follows: COD of 2580.7-2710.9 mg/L, TPh of $355.4-403.6 \mathrm{mg} / \mathrm{L}, \mathrm{NH}_{3}-\mathrm{N}$ of $182.1-259 \mathrm{mg} / \mathrm{L}, \mathrm{pH}$ of 7-7.2 and $\mathrm{BOD}_{5} / \mathrm{COD}$ of $0.22-0.28$. Phenolic compounds were the primary organic pollutants, accounting for $50-60 \%$ of the COD. The crude phenolic solution was obtained from the same company. The seed sludge was gathered from the full-scale aerobic process in the same CGW treatment plant. The biosystem has been operating for over three years. The volatile suspended solids (VSS) in the reactors were around $3000 \mathrm{mg} / \mathrm{L}$, with VSS/SS ratio about 0.65 .

\section{Reactor Configuration}

Two replicate SBBRs (SBBR1 and SBBR2) were used to treat CGW with an effective volume of $3 \mathrm{~L}$. The inner diameter and total height were $9 \mathrm{~cm}$ and $21 \mathrm{~cm}$, respectively. The sheet molding compound packing (Aquatech water treatment Co., Ltd, Guangzhou) with surface area of $3000 \mathrm{~m}^{2} / \mathrm{m}^{3}$ and density of $0.95 \mathrm{~g} / \mathrm{cm}^{3}$ was dosed in SBBR with a filling ratio of $10 \%$. One cycle of the SBBR consisted of $0.25 \mathrm{~h}$ of influent addition, $7 \mathrm{~h}$ of anoxic stage, $3 \mathrm{~h}$ of aerobic stage, $1.5 \mathrm{~h}$ of settling and $0.25 \mathrm{~h}$ of effluent withdrawal. The CGW was pumped into the anoxic phase and mixed by a motor stirrer, and air was introduced into the SBBR at the aerobic phase by an aeration pump. The dissolved oxygen (DO) concentrations at the aerobic stage and anoxic stage were 2.0-3.0 mg/L and $0-0.5 \mathrm{mg} / \mathrm{L}$, respectively. The temperature in the 
laboratory was kept at about $25^{\circ} \mathrm{C}$ during the whole operational period, which was controlled by airconditioning in summer and by central heating in winter.

\section{Start-Up and Operational Strategies of Bioaugmentation}

SBBR1 was set as the bioaugmentation group while SBBR2 was the control group. During the startup period, the system operation was divided into five different phases and the discharge ratio was increased to a higher level at the beginning of each phase. In order to establish suitable conditions for the rapid formation of biofilm, influent $\mathrm{COD}, \mathrm{TPh}$ and $\mathrm{NH}_{3}-\mathrm{N}$ concentrations were increased progressively at the start-up stage.

The PDB (Stenotrophomonas sp. FF1, Klebsiella sp. FF2 and Enterobacter sp. FF3) was previously isolated in our laboratory. These bacteria were capable of converting refractory phenolic compounds into easilybiodegradable compounds. The inoculation dosage of PDB $\left(\mathrm{OD}_{600}=5-6\right)$ was $0.05 \% \mathrm{~mL} / \mathrm{L}$ wastewater. The ratio for FF1, FF2 and FF3 were 1:1:1. During start-up, the PDB was inoculated to SBBR1 in the first 6 days (one time a day). In the phenolic inhibition experiments, the PDB was inoculated into SBBR1 on day 63 for remediation.

\section{Impact of Phenol Inhibition on SBBR}

The impact of phenolic compounds on SBBR was investigated by adding an appropriate amount of crude phenols on a pseudo-steady state period. The recovery time was defined as the interval between the end day of each phenolic impact and the point when COD, TPh and $\mathrm{NH}_{3}-\mathrm{N}$ removal efficiencies returned to the control level.

\section{Analytical Methods}

COD, BOD, $\mathrm{TPh}$ and $\mathrm{NH}_{3}-\mathrm{N}$ were all analyzed following standard methods (section $5220 \mathrm{D}, 5210 \mathrm{~B}$, $5530 \mathrm{D}$ and $4500 \mathrm{G}$, respectively) [17]. $\mathrm{DO}$ and $\mathrm{pH}$ values were determined with a hybrid meter $(30 \mathrm{~d}$, $\mathrm{HACH}$, USA). Organic compositions were analyzed using the GC-MS method. The detailed procedures were described in a previous study [18]. The samples were centrifuged at $12000 \mathrm{rpm}$ for $5 \mathrm{~min}$. Then the crushed cells were resuspended. The mixture after pretreatment was extracted with an equivalent volume of ethyl acetate, and evaporated to dryness and dissolved in $2 \mathrm{~mL}$ of $50 \%$ acetonitrile for subsequent analysis of bioassay for acyl-homoserine lactones (AHLs). Violacein and $\beta$-Galactosidase ( $\beta$-Gal) produced by Chromobacterium violaceum strain CV026 and Agrobacterium tumefaciens strain NTL4 were used to indicate the presence of short-chain and longchain AHLs, respectively. The violacein and $\beta$-Gal were determined according to the methods reported by previous researchers [16, 19].

\section{Bacterial Community Structure Analysis}

To investigate the positive effect of bioaugmentation on a bacterial community, samples were collected from SBBR at the end of a relatively stable operation stage. The DNA extraction, PCR amplification and DGGE analysis of sequencing data were obtained according to our previous study [10]. To analyze the proportion of dominant populations, FISH assay was adopted in the experiments. The samples collected at the end of the relatively stable operation stage were processed and oligonucleotide probes used for FISH experiments were selected by the method of Ma et al. [20].

\section{Results and Discussion}

\section{Performance Improvement of SBBR Augmented with PDB}

\section{Pollutant Removal of SBBRs during Start-Up}

Start-up procedure was important and necessary for newly built or upgraded wastewater treatment processes in order to acclimate to an inclement environment, especially for toxic and refractory wastewater. To evaluate the effect of bioaugmentation with PDB on start-up, pollutant removal efficiencies and

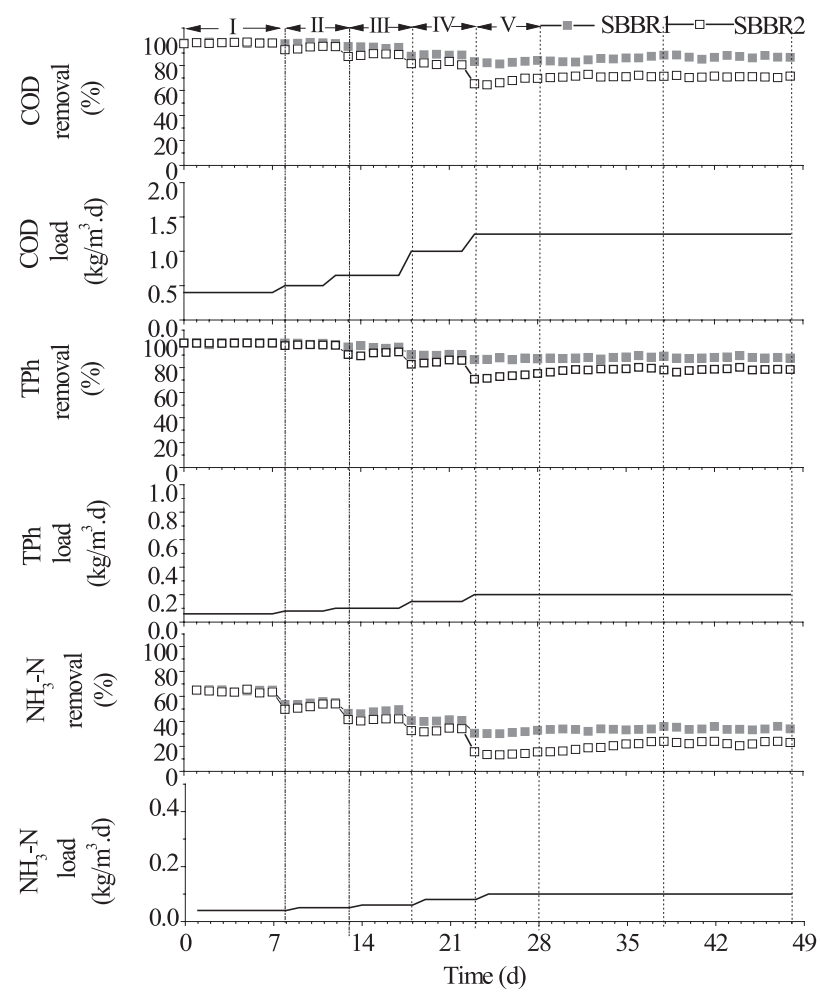

Fig. 1. Removal efficiencies of COD, TPh and $\mathrm{NH}_{3}-\mathrm{N}$ in SBBR during start-up. 


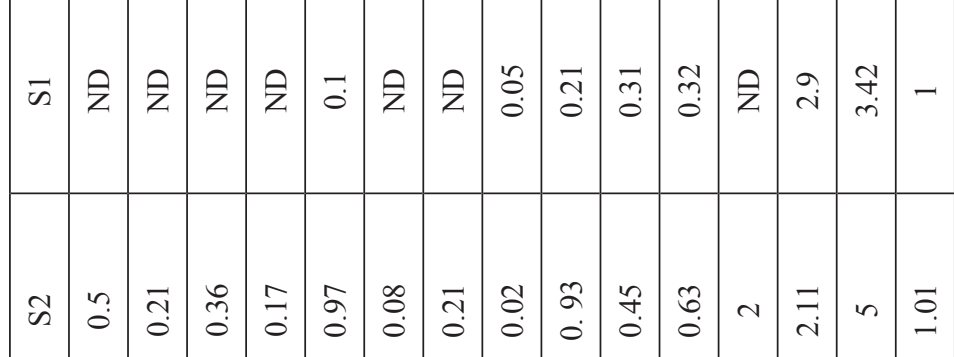

莺

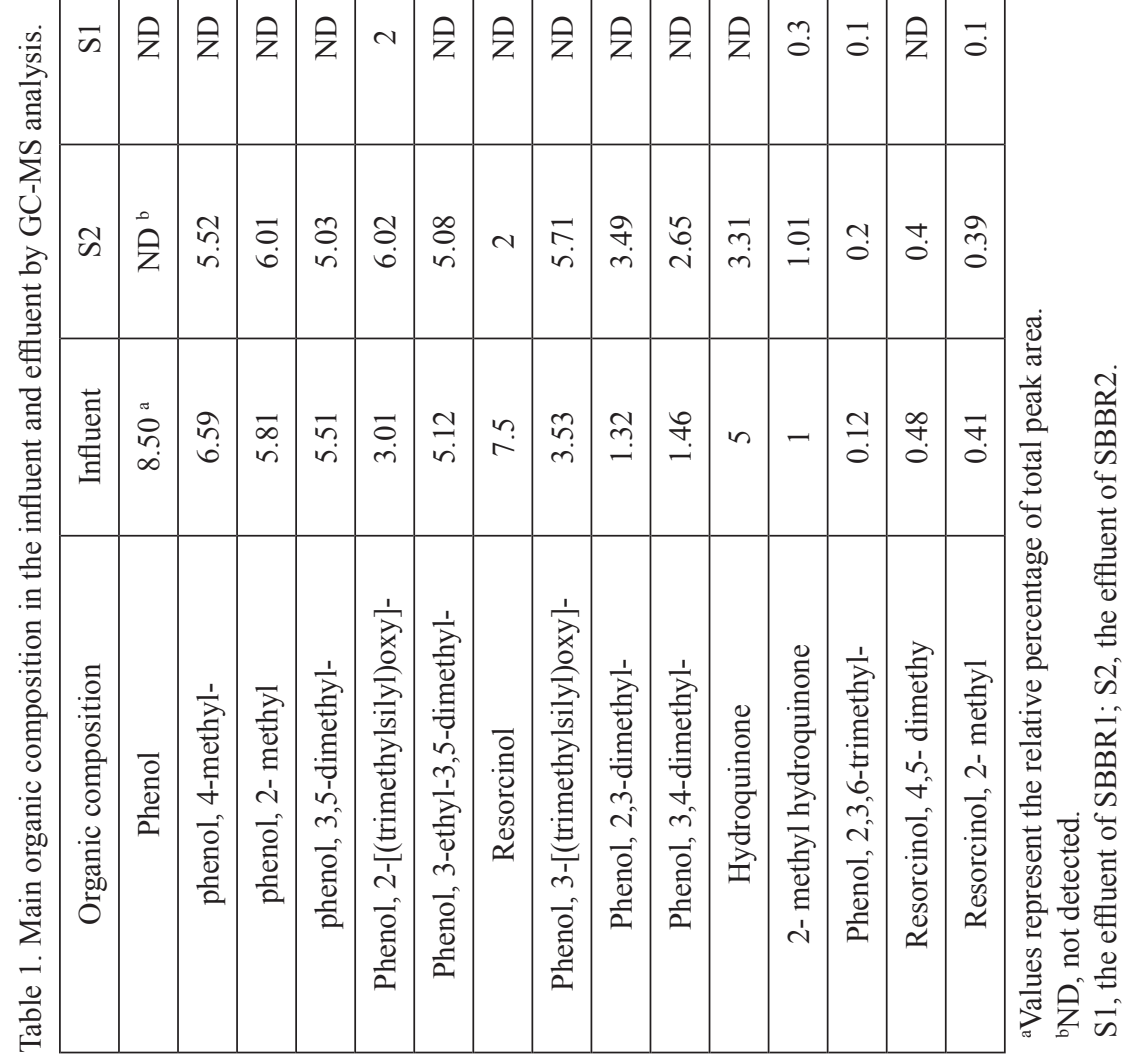


compound degradation characteristics in SBBRland SBBR2 were compared in the present study. The average removal efficiencies of $\mathrm{COD}, \mathrm{TPh}$ and $\mathrm{NH}_{3}-\mathrm{N}$ during start-up are shown in Fig. 1. During the whole process, the average COD and TPh removal efficiencies of SBBR1 were apparently higher than those of SBBR2. Meanwhile, due to enhanced inhibition of toxic substances with the influent load increased, the $\mathrm{COD}$ and $\mathrm{TPh}$ removal efficiencies of SBBR1 and SBBR2 decreased from $99.5 \%$ and $98.0 \%$ to $89.1 \%$ and $86.9 \%$, and from $99.7 \%$ and $98.0 \%$ to $78.0 \%$ and $70.5 \%$, respectively. More seriously, the $\mathrm{NH}_{3}-\mathrm{N}$ removal efficiencies of SBBR1 and SBBR2 decreased from $64.5 \%$ to $35.2 \%$ and from $65 \%$ to $23 \%$, respectively. In comparison to SBBR1, the pollutant removal of SBBR2 suffered higher inhibition at the start of each suddenly raised loading. As a result, it took 25 and 38 days respectively for SBBR1 and SBBR2 to retain stable pollutant removal. This demonstrated that bioaugmentation with PDB is an effective strategy for shortening the start-up period as well as improving the performance of pollutant removal.

The organic compositions transformation in SBBR1 and SBBR2 identified by GC-MS were compared in Table 1. According to previous studies [21, 22], the hydroxyphenols and methylphenols (such as resorcinol,
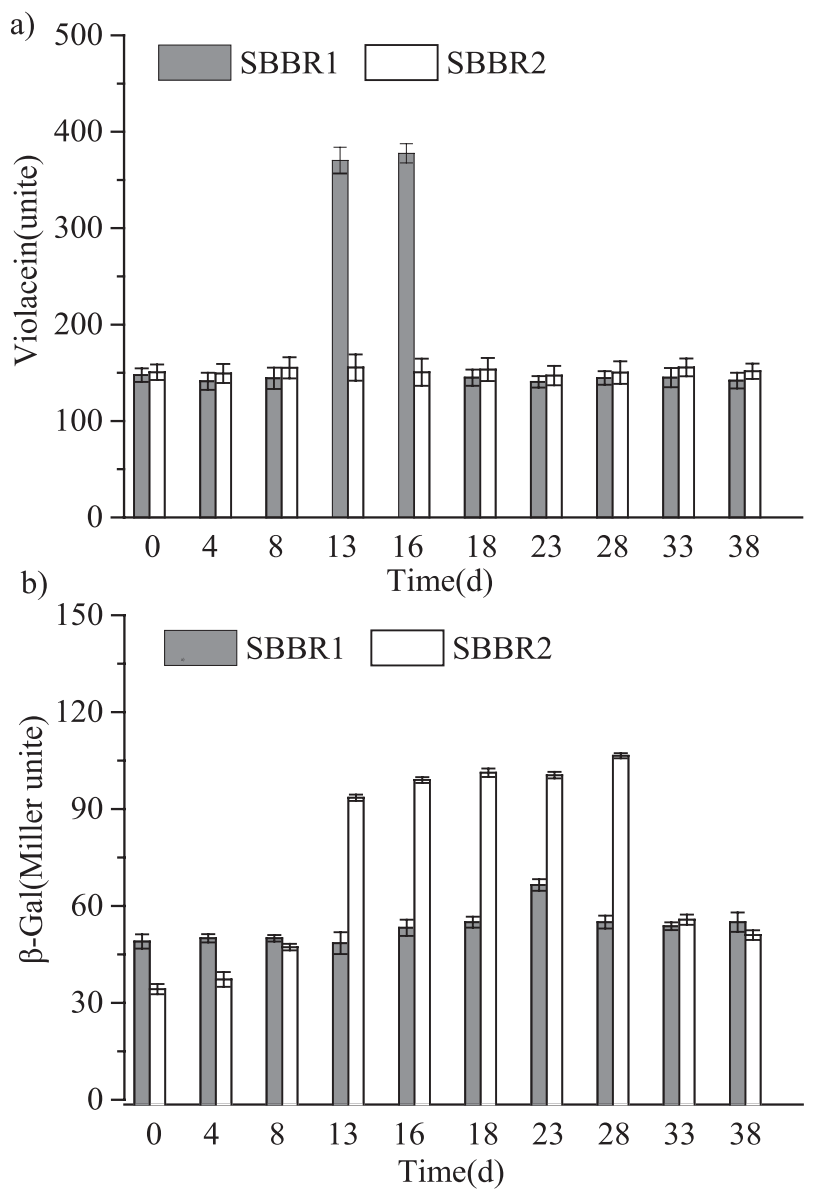

Fig. 2. Violacein content and $\beta$-Gal activity in SBBR during start-up. hydroquinone, 4-methyl-phenol, and 3,5-dimethylphenol), were much more toxic and refractory than phenol, and these bio-resistant organics were major components in the influent. Obviously, the phenolic compounds were degraded by SBBRs, and the relative amounts of toxic compounds in the effluent from SBBR1 were apparently less than from SBBR2. Notably, some refractory heterocyclic organics (2,5-furandicarboxaldehyde, 4-methyl-3-phenylPyrazole, etc.) and long-chain alkanes (octacosane, heptacosane, etc.) increased after SBBR2 treatment, indicating the insufficient biodegradation capacity on complicated chemicals. On the contrary, the SBBR1 exhibited superior removal efficacy with PDB bioaugmentation.

\section{Autoinducer Changes in SBBRs during Start-Up}

A sharp increase of autoinducers can directly reflect behavior changes in the bio-community [15]. Thus, short-chain AHLs and long-chain AHLs were detected during the start-up of SBBR. As shown in Fig. 2a), the content of violacein in the extracts from SBBR1 were sharply over 370 units from day 13 to day 16, which indicated that biofilm formed rapidly during this period, whereas the violacein content of SBBR2 stabilized in the range of 147 to 156 units throughout the process, implying a weaker biofilm formation capacity under toxic stress. Drastic changes of violacein content in SBBR1 should be attributed to bioaugmentation with PDB, thereby accelerating biofilm formation, strengthening biosystem resistance and shortening startup time [23]. Combined with higher biofilm biomass (data not shown), SBBR1 maintained a more sufficient degradation capacity, resulting in enhanced pollutant removal. Besides, as a long-chain AHL indicator, the activity change of $\beta$-Gal was depicted in Fig. $2 b$ ). The induced $\beta$-Gal in SBBR2 was raised dramatically at day 18 , with its concentration increased approximately three times than initial value (35.25 \pm 1.60$)$. Afterward, the $\beta$-Gal concentration was usually about 100 miller unite until day 27 and returned to its initial level at day 35. The induced $\beta-$ Gal in the extracts from SBBR1 displayed relatively lower changes, with the maximum concentration of only 66.5 units at day 23 and rapidly decreased to initial level (approx 55 units) at day 28. Based on a previous report [24], long-chain AHLs were conductive to phenolic compound degradation by activated sludge. In this study, the discharge ratio increased stepwise from day 7 to day 23, with influent $\mathrm{TPh}$ load increasing from $0.06 \mathrm{~kg} /\left(\mathrm{m}^{3} \cdot \mathrm{d}\right)$ to $0.2 \mathrm{~kg} /\left(\mathrm{m}^{3} \cdot \mathrm{d}\right)$. The dramatic fluctuation of long-chain AHLs in SBBR2 suggested severe toxic inhibition of phenols on activated sludge, and the bioaugmented system also experienced phenolic stress [25]. However, the $\beta$-Gal concentration of SBBR1 revealed much lower variability and rapidly returned to initial level on day 28 , indicating that SBBR1 augmented with PDB obtained stronger adaptability for shock loading. 


\section{Performance Robustness of SBBR Augmented with PDB}

\section{Stability Performance under Relatively Stable Influent}

To evaluate the lasting effectiveness of bioaugmentation with PDB, the performances of SBBR1 and SBBR2 for pollutant removal were compared in a long-term test with relative stable influent. The results showed that the removal efficiencies of $\mathrm{COD}, \mathrm{NH}_{3}-\mathrm{N}$ and $\mathrm{TPh}$ were always higher in SBBR1 than that in SBBR2. The removal efficiencies of COD, TPh and $\mathrm{NH}_{3}-\mathrm{N}$ for SBBR1 were stable at $86 \%, 89 \%$ and $35 \%$, respectively, compared to $70 \%, 75 \%$ and $22 \%$ for SBBR2.

\section{Stability Performance under Phenolic Inhibition}

The phenolic inhibition experiment was conducted on a pseudo-steady state period. As shown in Fig. 3, the first shock load $\left(\mathrm{TPh}=1 \mathrm{~kg} /\left(\mathrm{m}^{3} \cdot \mathrm{d}\right), \mathrm{COD}=5 \mathrm{~kg} /\left(\mathrm{m}^{3} \cdot \mathrm{d}\right)\right)$ on day 2 resulted in a remarkable disturbance on the performance of SBBRs. The $\mathrm{COD}, \mathrm{TPh}$ and $\mathrm{NH}_{3}-\mathrm{N}$ removal efficiencies in SBBR1 decreased to $60.5 \%$, $63.7 \%$ and $10.2 \%$, while the corresponding values in SBBR2 were $49.1 \%, 60.6 \%$ and $7.3 \%$, respectively. However, the performances of SBBR1 and SBBR2 were both rapidly recovered to the control level, as the influent load of COD and TPh dropped to $1.25 \mathrm{~kg} /\left(\mathrm{m}^{3} \cdot \mathrm{d}\right)$ and $0.2 \mathrm{~kg} /\left(\mathrm{m}^{3} \cdot \mathrm{d}\right)$ respectively on day 3 . After the first shock load, the systems were operated continuously for 7 days. Afterwards, the second transient shock load with $\mathrm{TPh}$ of $3 \mathrm{~kg} /\left(\mathrm{m}^{3} \cdot \mathrm{d}\right)$ and COD of $10 \mathrm{~kg} /\left(\mathrm{m}^{3} \cdot \mathrm{d}\right)$ was introduced on day 10 , which caused serious inhibition on the performance of SBBR. The removal efficiencies of COD, TPh and $\mathrm{NH}_{3}-\mathrm{N}$ in SBBR1 were sharply decreased to $47.3 \%, 51.1 \%$ and $6.0 \%$, respectively. Correspondingly, the removal efficiencies in SBBR2 were much lower, with $\mathrm{COD}, \mathrm{TPh}$ and $\mathrm{NH}_{3}-\mathrm{N}$ of $29.5 \%$, $33.8 \%$ and $1.0 \%$, respectively. The SBBR2 exhibited poorer resistance to the phenolic toxicity, especially for $\mathrm{NH}_{3}-\mathrm{N}$ removal. As a result, it took 10 days and 14 days respectively for SBBR1 and SBBR2 recovering to the control level. The continuous shock occurred from day

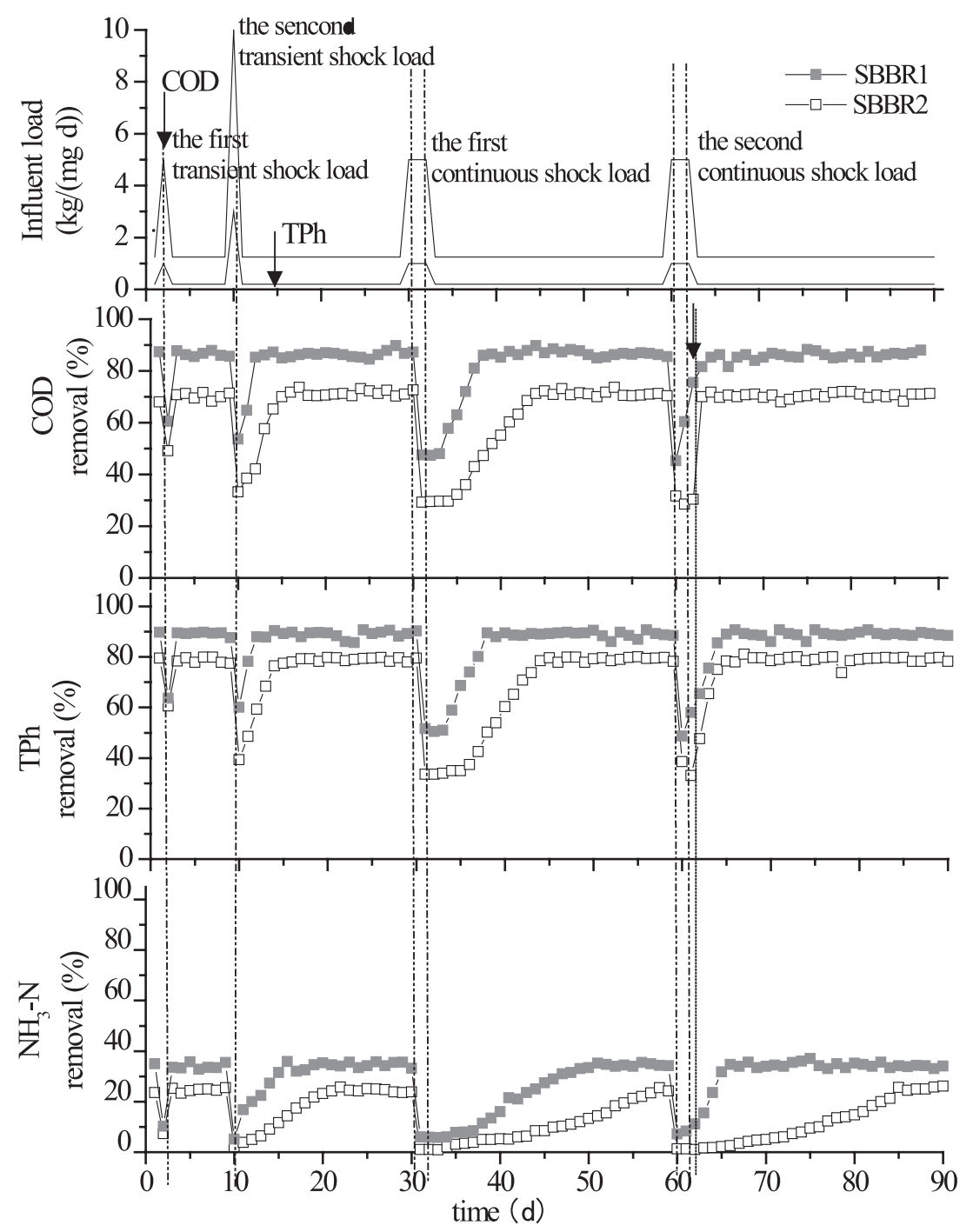

Fig. 3. Impact of phenol inhibition on SBBR with or without bioaugmentation, 
31 to 33 , with $\mathrm{TPh}$ load of $1 \mathrm{~kg} /\left(\mathrm{m}^{3} \cdot \mathrm{d}\right)$ and COD load of $5 \mathrm{~kg} /\left(\mathrm{m}^{3} \cdot \mathrm{d}\right)$. As for COD, TPh and $\mathrm{NH}_{3}-\mathrm{N}$ removal in this shock time, they were similar to those in the second shock load, but the time consumed during recovery was about two times more than the second shock. For SBBR2, the inhibition on $\mathrm{NH}_{3}-\mathrm{N}$ removal lasted for about 25 days, whereas the recovery period for SBBR1 was 16 days. The results showed that SBBR1 augmented with PDB performed higher resistance to phenol inhibition than the non-augmented SBBR2. In addition, $\mathrm{NH}_{3}-\mathrm{N}$ removal was a limiting factor for the recovery. The PDB remediation under phenolic inhibition was conducted in the second continuous shock load from day 60 to 62 , with $\mathrm{COD}$ of $5 \mathrm{~kg} /\left(\mathrm{m}^{3} \cdot \mathrm{d}\right)$ and $\mathrm{TPh}$ of $1 \mathrm{~kg} /\left(\mathrm{m}^{3} \cdot \mathrm{d}\right)$. The PDB of $0.05 \%$ was inoculated into SBBR1 on day 63. As a result, the performance of SBBR1 was improved, with recovery time shortened to 6 days. This indicated that bioaugmentation with PDB might be a promising strategy for biosystem recovery after phenol inhibition.

\section{Autoinducer Changes in SBBRs during Phenolic Inhibition}

In the phenolic inhibition test, behavior changes in the community were investigated through detected

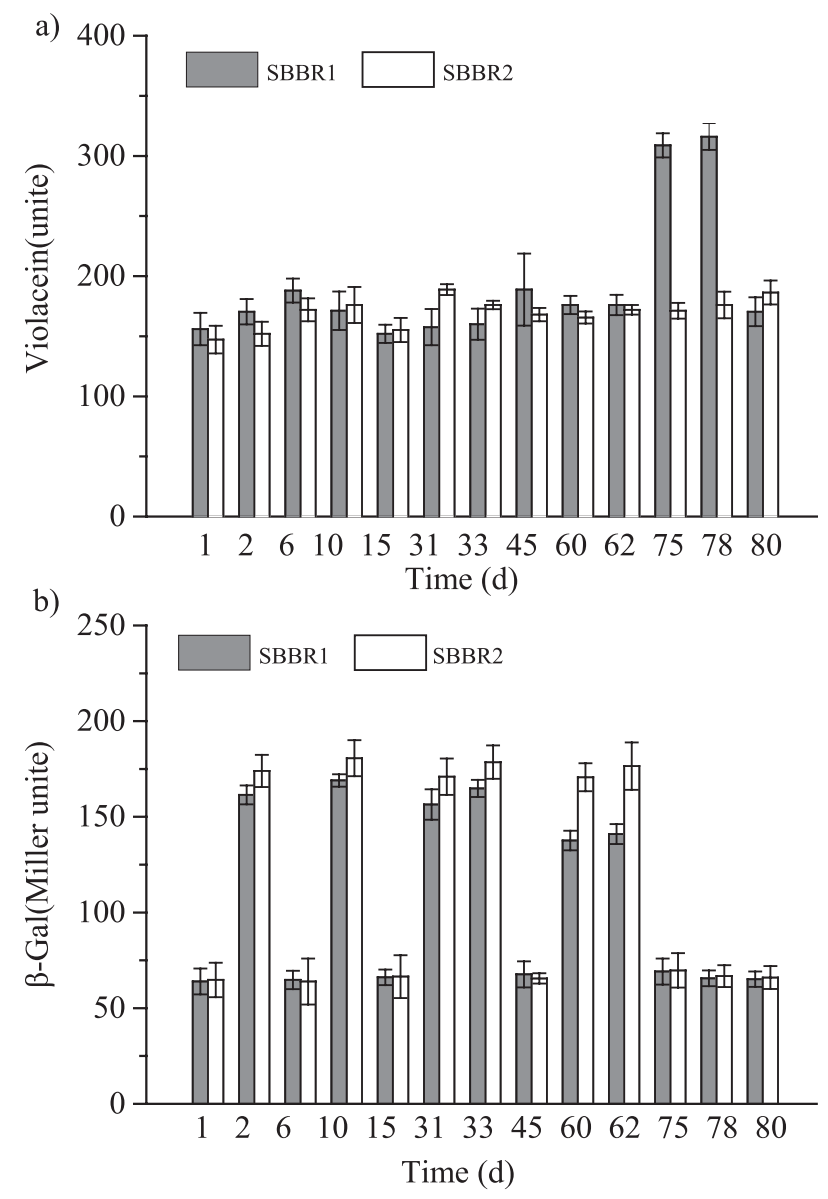

Fig. 4. Violacein content and $\beta$-Gal activity in SBBR under phenol inhibition. violacein content and $\beta$-Gal activity. As depicted in Fig. $4 \mathrm{a}$ ), the violacein content in the extracts from SBBR2 stabilized in the range of 147 to 186 units throughout the process. On the contrary, the content of induced violacein in SBBR1 was sharply increased over 306 units on day 75 to day 78 , which might be attributed to PDB inoculation on day 62. The phenomena provided further evidence for the positive influence of PDB bioaugmentation. As shown in Fig. $4 b$ ), the induced $\beta$-Gal activities of both reactors were significantly increased with dramatically raised shock load, suggesting profound phenolic stress on the biosystems. The induced $\beta$-Gal activity of SBBR1 was always lower than SBBR2. Moreover, with PDB inoculation on day 62 , the induced $\beta$-Gal activity in the extracts from SBBR1 showed relatively lower changes. The results demonstrated that PDB equipped SBBR with stronger resistance for phenolic inhibition.

\section{Microbial Community Structure Analysis}

Based on Fig. 5a), the apparent differences of bacterial communities between SBBR1 and SBBR2 were observed by detecting PCR-DGGE profiles. The bacterial communities in SBBR1 presented a clear separation with those from SBBR2 (Fig. 5b), revealing only a $32.4 \%$ similarity. The biofilm and sludge bands detected in SBBR2 shared 59.8\% similarity, while $65.5 \%$ of similarity was achieved in SBBR1. This significant difference was in close relation with the bacteria compositions and - in particular - the PDB in

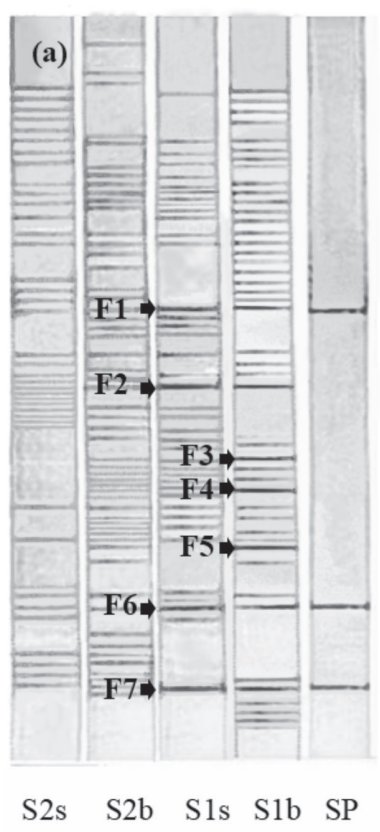

(b)

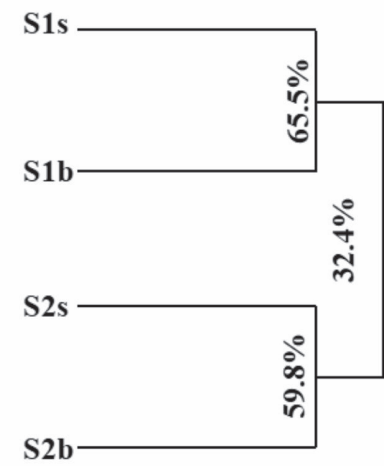

Fig. 5. Analysis of PCR-DGGE and cluster analysis based on percent similarity. a) PCR-DGGE profiles; b) cluster analysis based on percent similarity. S1s, S1b: biofilm and sludge community in SBBR1; S2s, S2b: biofilm and sludge community in SBBR2; SP: PDB (in this research). 
Table 2. Biodiversity estimation based on 16S rRNA clone libraries.

\begin{tabular}{|c|c|c|c|}
\hline Samples & OTUs & Diversity index & Evenness \\
\hline $\mathrm{S} 1_{\mathrm{S}}$ & 25 & 3.22 & 0.927 \\
\hline $\mathrm{S} 1_{\mathrm{b}}$ & 29 & 3.32 & 0.951 \\
\hline $\mathrm{S} 2_{\mathrm{S}}$ & 32 & 3.44 & 0.964 \\
\hline $\mathrm{S} 2_{\mathrm{b}}$ & 37 & 3.61 & 0.972 \\
\hline
\end{tabular}

S1b, S1s: biofilm and sludge community in SBBR1; S2b, S2s: biofilm and sludge community in SBBR2.

SBBR1 represented a positive effect on the promotion of wider bacteria attachment on the biofilm. Furthermore, the samples from SBBR1 showed seven significantly dominant populations, and several intensive bands could be observed. Similar dominant populations were detected in our previous study, which might attributed to seed sludge from the same CGW treatment plant.

In the dominant populations, the PDB appeared as bands F1, F2 and F6 in Fig. 5a). Relying on the previous literature [26-28], bands F2 and F3 were identified as strains of Pseudomonas aeruginosa and Acinetobacter, which were proven to be efficient in degrading phenolic compounds. Besides, bands F4 and F5 were identified as strains of Nitrospira and Nitrobacter, which could co-metabolize phenolic compounds and ammonia in industrial wastewater [11]. In order to further investigate biodiversity of biofilm and activated sludge, DGGE gels were interpreted by operational taxonomic units (OTUs), relative distributions (evenness) and values of Shannon diversity index. As Table 2 listed, the biodiversity of biofilm and activated sludge in SBBR1 were much more abundant than that in SBBR2. The remarkable biodiversity difference might be attributed to the inducement of PDB into SBBR1, which dramatically co-metabolized phenolic compounds. As a result, the inhibited effect of phenolic compounds on other impressible bacterial species were weakened.

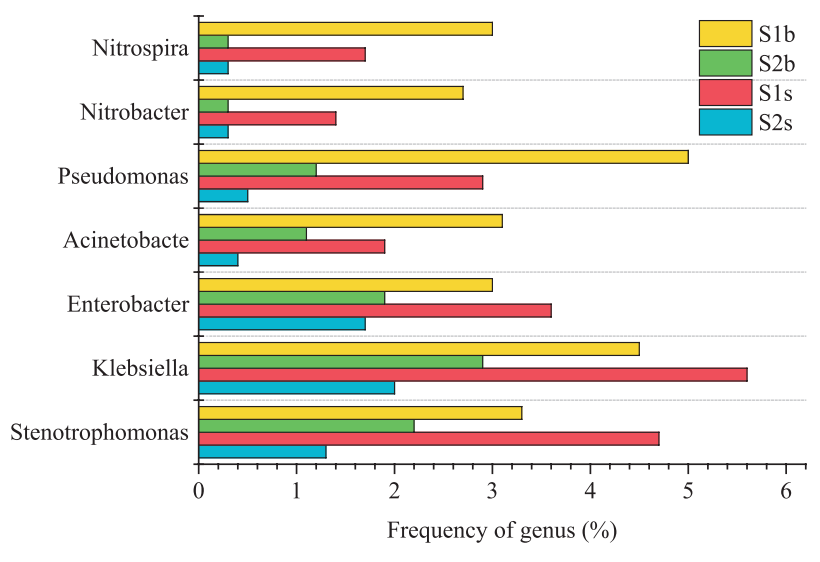

Fig. 6. Microbial community structure for different samples in genus level. S1s, S1b: biofilm and sludge community in SBBR1; S2s, S2b: biofilm and sludge community in SBBR2; SP: PDB (in this research).

FISH was investigated and the results were summarized in Table 3 and Fig. 6. Very high proportions of PDB (13.9\% in water and $10.8 \%$ in biofilm) were detected in SBBR1. In addition, the proportions of Pseudomonas aeruginosa and Acinetobacter in water and in biofilm were $8.1 \%$ and $4.8 \%$ respectively, while the proportions in SBBR2 were $2.3 \%$ and $1 \%$ correspondingly. Nitrospira and Nitrobacter were identified as the main bacteria involving ammonia oxidation, which also showed a higher proportion in SBBR1 (2.1\% in water and $5.9 \%$ in biofilm) than in SBBR2 $(<0.1 \%)$. This indicated an enhanced ammonia removal in SBBR1 owing to the improvement of nitrification, and this was consistent with the results of Fig. 1. Thus, the addition of PDB into SBBR1 played an important role in reducing the negative influences of phenolic compounds on ammonia oxidation bacteria, and it also evidenced that biofilm was beneficial for the survival of ammonia nitrogen populations [29].

Table 3. Composition of bacteria in samples defined by areas of group-specific probes over EUB mix probe.

\begin{tabular}{|c|c|c|c|c|}
\hline Samples & S1s (\%) & S1b (\%) & S2s (\%) & S2b (\%) \\
\hline Klebsiella & 2.0 & 5.6 & 2.9 & 4.5 \\
\hline Stenotrophomonas & 1.3 & 4.7 & 2.2 & 3.3 \\
\hline Enterobacter & 1.7 & 3.6 & 1.9 & 3.1 \\
\hline Acinetobacte & 0.4 & 1.9 & 1.1 & 3 \\
\hline Nitrospira & 0.3 & 1.7 & 0.3 & 2.7 \\
\hline Nitrobacter & 0.3 & 1.4 & 1.2 & 5.0 \\
\hline Pseudmonas & 0.5 & 2.9 & 90.1 & 75.4 \\
\hline Other bacteria & 93.5 & 78.2 & & \\
\hline
\end{tabular}

S1b, S1s: biofilm and sludge community in SBBR1; S2b, S2s: biofilm and sludge community in SBBR2. 


\section{Conclusions}

Bioaugmentation of SBBR with PDB was effective in shortening start-up time and improving stability of SBBR for $\mathrm{CGW}$ treatment. The higher removal efficiency of COD, TPh and $\mathrm{NH}_{3}-\mathrm{N}$ was mainly attributed to PDB augmentation. Besides, augmentation with $\mathrm{PDB}$ was a prolonged influence, which was also presented as being resistant to phenol inhibition. Microbial community analysis revealed that the PDB was presented as a dominant species, which contributed to the typical pollutant removal in the augmented SBBR. The discoveries in this study will facilitate successful development of such bioaugmentation systems.

\section{Acknowledgements}

This work was supported by the National Natural Science Foundation of China (No. 51708505), and the project was funded by the Research Fund of Tianjin Key Laboratory of Aquatic Science and Technology(TJKLAST-ZD-2018-02), the Zhejiang Provincial Natural Science Foundation of China (No. LQ17E080008) and the NSFC-Zhejiang Joint Fund for the Integration of Industrialization and Informatization (No. U1609214).

\section{Conflict of Interest}

The authors declare no conflict of interest.

\section{References}

1. GAI H., JIANG Y., QIAN Y., KRASLAWSKI A. Conceptual design and retrofitting of the coal-gasification wastewater treatment process. Chem. Eng. J. 138 (1-3), 84, 2008.

2. ZHU H., HAN Y., XU C., HAN H., MA W. Overview of the state of the art of processes and technical bottlenecks for coal gasification wastewater treatment. Sci. Total Environ. 637-638, 1108, 2018.

3. JI Q., TABASSUM S., HENA S., SILVA C.G., YU G., ZHANG Z. A review on the coal gasification wastewater treatment technologies: past, present and future outlook. J. Clean. Prod. 126, 38, 2016.

4. ZHAO Q., LIU Y. State of the art of biological processes for coal gasification wastewater treatment. Biotechnol. Adv. 34 (8), 1442, 2016.

5. WANG W., WANG S., REN X., HU Z., YUAN S. Rapid establishment of phenol- and quinoline-degrading consortia driven by the scoured cake layer in an anaerobic baffled ceramic membrane bioreactor. Environ. Sci. Pollut. R. 24 (33), 26125, 2017.

6. ZHENG M., ZHU H., HAN Y., XU C., ZHANG Z., HAN $\mathrm{H}$. Comparative investigation on carbon-based moving bed biofilm reactor (MBBR) for synchronous removal of phenols and ammonia in treating coal pyrolysis wastewater at pilot-scale. Bioresour Technol. 288, 121590, 2019.
7. ZHENG M., HAN Y., XU C., HAN H., ZHANG Z. Discrimination of typical cyclic compounds and selection of toxicity evaluation bioassays for coal gasification wastewater (CGW) based on toxicity mechanism of actions (MOAs). Sci. Total Environ. 644, 324, 2018.

8. JIA S., HAN H., ZHUANG H., HOU B. The pollutants removal and bacterial community dynamics relationship within a full-scale British Gas/Lurgi coal gasification wastewater treatment using a novel system. Bioresour Technol. 200, 103, 2016.

9. CYCON M., MROZIK A., PIOTROWSKA-SEGET Z. Bioaugmentation as a strategy for the remediation of pesticide-polluted soil: A review. Chemosphere. 172, 52, 2017.

10. FANG F., HAN H., ZHAO Q., XU C., ZHANG L. Bioaugmentation of biological contact oxidation reactor (BCOR) with phenol-degrading bacteria for coal gasification wastewater (CGW) treatment. Bioresour Technol. 150, 314, 2013.

11. XU C., HAN H., JIA S., ZHAO Q. Influence of phenol on ammonia removal in an intermittent aeration bioreactor treating biologically pretreated coal gasification wastewater. J. Environ. Sci.-China. 43, 99, 2016.

12. WANG W., WU B., PAN S., YANG K., HU Z., YUAN S. Performance robustness of the UASB reactors treating saline phenolic wastewater and analysis of microbial community structure. J. Hazard. Mater. 331, 21, 2017.

13. ZHU X., LIU R., LIU C., CHEN L. Bioaugmentation with isolated strains for the removal of toxic and refractory organics from coking wastewater in a membrane bioreactor. Biodegradation. 26 (6), 465, 2015.

14. TANG X., GUO Y., ZHU T., TAO H., LIU S. Identification of quorum sensing signal AHLs synthases in Candidatus Jettenia caeni and their roles in anammox activity. Chemosphere. 225, 608, 2019.

15. MORUZZI R.B., DA SILVA P.G., SHARIFI S., CAMPOS L.C., GREGORY J. Strength assessment of Al-Humic and Al-Kaolin aggregates by intrusive and non-intrusive methods. Sep. Purif. Technol. 217, 265, 2019.

16. ZHNAG Z., CAO R., JIN L., ZHU W., JI Y., XU X., ZHU $\mathrm{L}$. The regulation of $\mathrm{N}$-acyl-homoserine lactones (AHLs)based quorum sensing on EPS secretion via ATP synthetic for the stability of aerobic granular sludge. Sci. Total Environ. 673, 83, 2019.

17. APHA. Standard Methods for the Examination of Water and Wastewater, $20^{\text {th }}$ ed. A.P.H. Association, Washington, DC, USA. 1998.

18. SHI J., XU C., HAN Y., HAN H. Enhanced anaerobic biodegradation efficiency and mechanism of quinoline, pyridine, and indole in coal gasification wastewater. Chem. Eng. J. 361, 1019, 2019.

19. PONMUSAMY K., PAUL D., KWEON J.H. Inhibition of Quorum Sensing Mechanism and Aeromonas hydrophila Biofilm Formation by Vanillin. Environ. Eng. Sci. 26 (8), 1359, 2009.

20. MA Q., QU Y., SHEN W., ZHANG Z., WANG J., LIU Z., LI D., LI H., ZHOU J. Bacterial community compositions of coking wastewater treatment plants in steel industry revealed by Illumina high-throughput sequencing. Bioresour Technol. 179, 436, 2015.

21. WANG H., LI P., WANG Y., LIU L., YAO J. Metagenomic insight into the bioaugmentation mechanism of Phanerochaete chrysosporium in an activated sludge system treating coking wastewater. J. Hazard. Mater. 321, 820, 2017.

22. ZHENG M., HAN Y., XU C., ZHANG Z., HAN H. 
Selective adsorption and bioavailability relevance of the cyclic organics in anaerobic pretreated coal pyrolysis wastewater by lignite activated coke. Sci. Total Environ. 653, 64, 2019.

23. HU H., HE J., LIU J., YU H., ZHANG J. Biofilm activity and sludge characteristics affected by exogenous $\mathrm{N}$-acyl homoserine lactones in biofilm reactors. Bioresour Technol. 211, 339, 2016.

24. YONG Y., ZHONG J. Regulation of aromatics biodegradation by rhl quorum sensing system through induction of catechol meta-cleavage pathway. Bioresour Technol. 136, 761, 2013.

25. WANG J., HE H., WANG M., WANG S., ZHANG J., WEI W., XU H. Bioaugmentation of activated sludge with Acinetobacter sp. TW enhances nicotine degradation in a synthetic tobacco wastewater treatment system. Bioresour Technol. 142, 445, 2013.
26. KOTRESHA D., VIDYASAGAR G.M. Phenol degradation in a packed bed reactor by immobilized cells of Pseudomonas aeruginosa MTCC 4997. Biocatalysis and Agricultural Biotechnology. 10, 386, 2017.

27. SONG H., LIU Y., XU W., ZENG G., AIBIBU N., XU L., CHEN B. Simultaneous Cr(VI) reduction and phenol degradation in pure cultures of Pseudomonas aeruginosa CCTCC AB91095. Bioresour Technol. 100 (21), 5079, 2009.

28. SUN J., XU L., TANG Y., CHEN F., WU X. Simultaneous degradation of phenol and $n$-hexadecane by Acinetobacter strains. Bioresour Technol. 123, 664, 2012.

29. OOI G.T.H., ESCOLA M., ANDERSEN H.R., BESTER $\mathrm{K}$. Transformation products of clindamycin in moving bed biofilm reactor (MBBR). Water Res. 113, 139, 2017. 